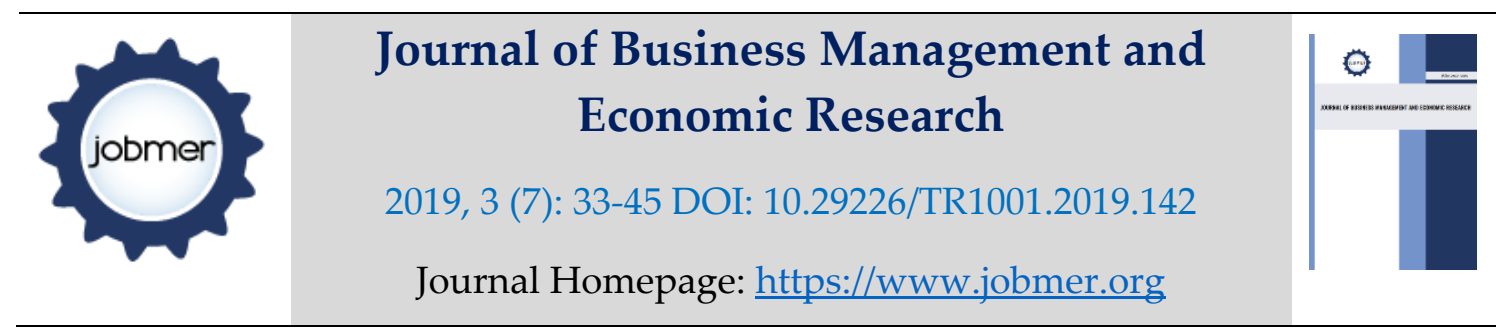

\title{
An Investigation of Negative Reviews on Tripadvisor about the Seafood Restaurants in Kyrenia
}

\section{Müjdat ERTÜRK}

Dr., Eskişehir Tepebaşı Ali Güven Vocational and Technical Anatolian High School

mujdate26@gmail.com

\begin{abstract}
In this research, negative reviews written on tripadvisor.com about the seafood restaurants in Kyrenia were examined. The average of the ratings of the restaurants is 4.14 on a 5 point scale. This average indicates high satisfaction. Customers wrote 938 reviews about the restaurants. Of the customers who wrote these reviews, $62 \%$ rated their experience as excellent, $24 \%$ as very good $7 \%$ as average, $3 \%$ as poor, and $4 \%$ as terrible. These ratings also indicate high satisfaction. Of all the reviews, 137 are negative. Of the customers who wrote these negative reviews, $3 \%$ rated their experience as excellent, $6 \%$ as very good, $45 \%$ as average, $18 \%$ as poor, and $29 \%$ as terrible. Of these negative reviews, $30 \%$ are about the dishes, $23 \%$ about the staff, $19 \%$ about the prices, $16 \%$ about the service, $6 \%$ about the service environment, and $6 \%$ about the menus.
\end{abstract}

Keywords: TRNC- Kyrenia, Seafood Restaurants, TripAdvisor, Negative Reviews, Complaints

\section{Introduction}

Today, the internet is a phenomenon that provides the fastest communication and helps the development of technologies that can be applied in all areas. The internet offers various opportunities for service businesses to increase their number of customers and strengthen their communication with their existing customers. It is quite essential for customer relations management that businesses follow the social networks on the internet and respond to all the positive or negative comments about their businesses.

Today, customer experience has an important place for social and economic life (Quan and Wang, 2004). Customer experience is defined as the direct or indirect experience of customers about a company (Meyer and Schwager 2007). Customer loyalty, customer lifetime value and the establishment of a long-term relationship based on mutual trust between customers and 
businesses are of paramount importance for businesses to achieve competitive advantage (Morgan and Hunt, 1994). A relationship based on mutual trust between customers and companies is directly related to customer satisfaction. Customer satisfaction indicates that customers' expectations before consumption are met after their service experience (Westbrook, 1980).

Informal transfer of information about a product, service or business from a customer to another are defined as word of mouth marketing. Along with the diversification of websites on the internet, consumers have begun to use the internet to learn about the product they are considering buying or the business they are considering buying from. Thus, this concept, which is also referred to as the electronic word of mouth communication, has become widespread (Jeong and Jang 2011: 356-357). Some studies have reported that because consumers' comments, opinions, and recommendations have become very important, nowadays, electronic word of mouth communication is effective on consumer purchase decisions (Sotiriadis and Van Zyl 2013; Bae and Lee 2011; Zeng and Gerritsen 2014).

Tripadvisor.com, one of the social networks on the internet, is one of the most important sites in terms of electronic word of mouth communication for businesses operating in all areas of tourism. tripadvisor.com, a website where anyone who has benefitted from the services of an enterprise can easily write reviews about and rate that enterprise, is nowadays highly effective in the purchase decision of many consumers. In this respect, reviews on this site, especially negative reviews may probably become very crucial for organizations.

\section{Conceptual Framework and Literature Review}

The behaviours of customers, whose expectations about a product or a service are not met or who feel dissatisfied, towards that service or the products of the organization are called consumer complaints (Singh and Pandya, 1991). Studies on consumer complaint behaviour can be classified under the following general headings: types of consumer complaint behaviours, causes of complaints, companies' efforts to compensate for product and service errors, customer relationship management, and complaint management systems in organizations (Singh, 1988; Crie, 2003; Grougiou and Pettigrew, 2009; Dahl and Peltier, 2015). Research conducted to determine the reasons of consumer complaint behaviour showed that personal factors might result in complaints. These factors can be summarized as personality traits, demographic 
characteristics, and attitudes towards complaints (Fornell and Westbrook, 1979; Jacoby and Jaccard, 1981; Singh, 1990). Consumer interaction styles, which are included in personal characteristics, are defined as consistent behaviour patterns that consumers exhibit to achieve the desired result regarding consumption behaviour (Richins, 1983). Consumer interaction styles are examined in two sub-categories: "self-assurance" and "aggressiveness" (Richins, 1987).

Dissatisfied consumers can file a direct or indirect complaint about an organization (Kim et al., 2003). It has been determined that consumers usually express their reactions in three different ways: to complain directly to the enterprise, to complain to other people and various consumer organizations, or to file complaints to the judiciary (Barlow and Moller 1998; DeFranco et al. 2005). According to Mattila and Wirtz (2004), customers can make a complaint face-to-face and by telephone, or they may prefer to complain by letter and e-mail. Electronic word of mouth communication (e-wom) can be defined as the sharing of positive or negative information, comments, and experiences related to products and businesses online by old, current or potential customers (Hennig-Thurau et al., 2004). Consumers have different levels of risk perception in all consumption behaviours, and reference groups are the important tool to reduce this risk perception (Hussain et al., 2017). In today's consumption process, it is possible to say that the ewom communication channels are highly effective at every stage from the information search stage to the purchase decision (Moore, 2015; Erkan and Evans, 2016; Chen et al., 2016; Hussain et al., 2018). According to the results of Nielsen's (2015) research, sixty-nine per cent of consumers bases their purchasing decisions on online consumer reviews.

TripAdvisor is the world's largest social network which is used by the tourism industry and enables online word of mouth communication. TripAdvisor also offers enterprises the opportunity to respond to reviews. Online comments posted by users provide information about tourism businesses for past and future customers (Sparks and Bradley, 2014). tripadvisor.com provides its users with the opportunity to create profiles and comment on their experiences about a product or an enterprise. Users can rate their experiences as $1=$ terrible, $2=$ poor, $3=$ average, $4=$ very good, $5=$ excellent, and write reviews about their experience. Businesses can respond to these comments and communicate directly with customers and potential customers. With tripadvisor.com, consumers can search faster and more widely, and they can access more information according to their preferences and interests (Raguseo, 2017: 746). In their study, Xiang and Gretzel (2010) concluded that TripAdvisor is the most frequently used website among other electronic e-wom websites. 


\section{Method}

\subsection{Purpose and Importance of the Research}

The present study was conducted to examine the negative reviews on tripadvisor.com written by customers who visited the seafood restaurants in Kyrenia and thus help the restaurants create strategies for online complaint management. Kyrenia is the most important and most demanding region of TRNC in terms of Tourism. According to the figures 2018, the number of 25,241 beds in the TRNC is 16,077 , in other words $64 \%$ of them are in Kyrenia. $62 \%$ of the accommodation companies in TRNC operate in Kyrenia. $62 \%$ of the accommodation establishments throughout the TRNC are operating in Kyrenia. The largest number of food and beverage companies across the TRNC are operating in the Kyrenia region. Since it is the locomotive region of TRNC tourism, Kyrenia Region has been selected for research.To achieve this aim, negative reviews about these restaurants on tripadvisor.com were identified and grouped. Thus, the restaurants can see the subject of the negative reviews and will be able to compensate for them.

\subsection{Scope and Limitations}

The scope of the study was limited to the seafood restaurants in Kyrenia; the seafood restaurants in other parts of Cyprus were not included in the study.

\subsection{Population and Sample}

The population of the study consists of seafood restaurants in Kyrenia. Since it is not possible to reach all the customers who visited all the restaurants in Kyrenia and get their opinions, 32 seafood restaurants, which were rated and about which reviews were written on tripadvisor.com, were included in the sample, and all the reviews about these restaurants were examined.

\subsection{Data Collection and Analysis}

On https://www.tripadvisor.com.tr/Restaurants-g190378-Kyrenia_Kyrenia_District.html seafood restaurants option was selected, and 938 reviews, written as of March 15, 2018, about 32 seafood restaurants were reached, and it was determined that 137 of all the reviews were negative. Later, these 137 negative reviews were analysed through content analysis. As a result of the analysis, the negative reviews were categorized into six categories including 16 subjects of complaint. 


\section{Findings}

Until March 15, 2018, users had written reviews about 32 seafood restaurants in Kyrenia. All of these 32 restaurants were rated by the users. Of these restaurants, only one responded to the users. This restaurant responded to 106 of 141 reviews written about it.

Table 1. Average of Customers' Ratings

\begin{tabular}{lc}
\hline Dimension & Average \\
\hline Service & 4,14 \\
Price & 4,06 \\
Dishes & 4,14 \\
Atmosphere & 4,20 \\
\hline Total & $\mathbf{4 , 1 4}$ \\
\hline
\end{tabular}

Table 1 presents the averages of the ratings of 32 seafood restaurants in Kyrenia. The table indicates that the customers felt most satisfied with the atmosphere where they felt least satisfied with the price. The average of the ratings of all the dimensions is 4.14 on a 5 point scale.

Table 2. Distribution of Reviews by Ratings

\begin{tabular}{lcc}
\hline Rating & Number of Reviews & \% \\
\hline Excellent & 585 & 62 \\
Very Good & 223 & 24 \\
Average & 66 & 7 \\
Poor & 24 & 3 \\
Terrible & 40 & 4 \\
\hline Total & $\mathbf{9 3 8}$ & $\mathbf{1 0 0}$ \\
\hline
\end{tabular}

Table 2 presents the distribution of the number of reviews by customers' ratings. The table indicates that of all the customers who wrote the reviews about the restaurants, $62 \%$ rated them as excellent, $24 \%$ as very good, $7 \%$ as average, $3 \%$ as poor, and $4 \%$ as terrible. These figures indicate that $86 \%$ of customers are satisfied with the service they received.

Table 3. Distribution of Negative Reviews by Ratings

\begin{tabular}{lcc}
\hline Rating & Number of Reviews & \% \\
\hline Excellent & 4 & 3 \\
Very Good & 8 & 6 \\
Average & 61 & 45 \\
Poor & 24 & 18 \\
Terrible & 40 & 29 \\
\hline Total & $\mathbf{1 3 7}$ & $\mathbf{1 0 0}$ \\
\hline
\end{tabular}


Table 3 presents the distribution of negative reviews by ratings. The table indicates that of the customers who wrote these comments, $45 \%$ rated these restaurants as average whereas $3 \%$ rated them as excellent. All of the 'poor' or 'terrible' ratings are also together with negative reviews.

All of the customers who rated the restaurants as excellent (4) complained about the prices. Two of these negative reviews are as follows:

"The dishes were quite tasty, and everything was very good, but the prices were high."

"The dishes and the side orders were wonderful; it would have been perfect had the prices been a bit lower."

Of the customers who rated the restaurants as very good (8), three complained about the prices, four about the service-related problems, and one about the service environment. Four of these negative reviews are as follows:

"Everything was nice but extremely expensive."

"Excellent location and pretty good service. But it is a bit expensive compared to similar restaurants."

"The restaurant has a wonderful view; the menu and flavours are delicious, but the service is not so successful."

"The dishes, service, ambience were very nice, but we had to get out for fresh air as they allowed customers to smoke inside."

Table 4. Distribution of Negative Reviews by Category

\begin{tabular}{lcccc}
\hline Category & $\mathbf{n}$ & $\mathbf{\%}$ & $\mathbf{N}$ & $\mathbf{\%}$ \\
\hline 1. Negative reviews about the Dishes & & & $\mathbf{4 2}$ & $\mathbf{3 0}$ \\
Cooking Mistakes & 19 & 45 & & \\
Taste of Dishes & 20 & 48 & & \\
Small Size of Portions & 3 & 7 & & \\
\hline Total Categories & $\mathbf{4 2}$ & $\mathbf{1 0 0}$ & & \\
\hline 2. Negative reviews about the Staff & & & $\mathbf{3 1}$ & $\mathbf{2 3}$ \\
\hline Unresponsive Staff & 8 & 26 & & \\
Unclean Staff & 1 & 3 & & \\
Rude Staff & 9 & 29 & & \\
Quality of Staff & 4 & 15 & & \\
Discrimination of Customers & 9 & 29 & & \\
\hline Total Categories & $\mathbf{3 1}$ & $\mathbf{1 0 0}$ & & \\
\hline 3. Negative reviews about the Prices & \multicolumn{3}{|l}{$\mathbf{2 6}$} & $\mathbf{1 9}$ \\
\hline Expensive & $\mathbf{2 6}$ & 100 & & \\
\hline Total Categories & $\mathbf{2 6}$ & $\mathbf{1 0 0}$ & & \\
\hline 4. Negative reviews about the Service & & & $\mathbf{2 2}$ \\
\hline
\end{tabular}




\begin{tabular}{lcccc} 
Poor Service & 14 & 64 & & \\
Slow Service & 8 & 36 & & \\
\hline Total Categories & $\mathbf{2 2}$ & $\mathbf{1 0 0}$ & & \\
\hline 5. Negative reviews about the Service Environment & & & $\mathbf{8}$ & $\mathbf{6}$ \\
\hline Insufficient Cleaning & 4 & 50 & & \\
Insufficient Technology & 1 & 12,5 & & \\
Noise & 2 & 25 & & \\
Insufficient Equipment & 1 & 12,5 & & \\
\hline Total Categories & $\mathbf{8}$ & $\mathbf{1 0 0}$ & & \\
\hline 6. Negative reviews about the Menus & & & $\mathbf{8}$ & $\mathbf{6}$ \\
\hline Insufficient Menu & 8 & 100 & & \\
\hline Total Categories & $\mathbf{8}$ & $\mathbf{1 0 0}$ & & \\
\hline GRAND TOTAL & $\mathbf{1 3 7}$ & $\mathbf{1 0 0}$ & $\mathbf{1 3 7}$ & $\mathbf{1 0 0}$ \\
\hline
\end{tabular}

Table 4 presents the distribution of negative reviews by category. The table indicates that the customers mostly complained about the dishes (42 negative reviews- 30\%). The negative reviews about the dishes are mainly about the taste of the dishes (20 negative reviews- $48 \%$ ). Other negative reviews about the dishes are about cooking mistakes (19 negative reviews- $45 \%$ ) and the small size of portions (3 negative reviews- 7\%). Five of these negative reviews are as follows:

"The dishes couldn't be any worse. There is no service quality of Istanbul's worst places on an island like Cyprus."

"I ordered the fixed menu. Nothing was edible other than the salad and artichoke. The hot appetizers were overcooked. The calamari was like rubber."

"Half of those written on the menu did not show up, and those who were brought were in 'stingy' portions. Don't waste your time and money!"

"Not so bad, but the amounts of appetizers are quite low and the flavour is average; due to its location in the port, prices are slightly higher than in other parts of Cyprus."

"Well done meat for them is the meat that should be eaten starting from the middle; I could not even eat it, at least the cats were happy."

Also, the table indicates that the category with the second most negative reviews about is the staff category (31 negative reviews- 23\%). These negative reviews are mostly about 'rude staff' and 'discrimination of customers' (9 negative reviews each-29\%). Other negative reviews about the staff are about 'unresponsive staff' (8 negative reviews- $26 \%$ ), 'the quality of the staff' (4 negative 
Journal of Business Management and Economic Research (JOBMER), vol.3, issue.7, pp.33-45

reviews- $15 \%$ ), and unclean staff (1 negative review- $3 \%$ ). Five of these negative reviews are as follows:

"The location and the dishes were quite successful, but the unresponsive staff made us sad. We sat at our table, and after 15 minutes, they served one plate of olives and some bread. Then, we were about to change our opinions when they started to bring the side orders, but we had to ask four times for more bread, two times for coffee, and three times for the check. I hope responsible friends will take our warning into account."

"I don't know whether it was because we were the only table in the restaurant, but I had to stand up three times to go and get a clean glass. What is even more interesting was that when another table came, the rude man in a blue shirt who was called the "chief" (headwaiter) came to our table and scolded us for standing up or talking. It was quite shocking and offending."

"Mr. Waiter (!) said that he could not serve us the dishes we ordered because we should buy at least three sets of menus (?) because these tables are worth at least $400 \mathrm{TL}$. We said that we could not eat so much food with two children three and nine years of age and that we wanted to talk to the boss. It turns out this was the order of the boss, and they didn't even let us talk to the boss."

"The restaurant was on the seafront, and the quality of the dishes was above the average. However, we said that we would not drink alcohol; the attitude of the headwaiter towards us was so annoying that we will never eat there even if the food was free and offered on a golden tray. Not every customer in a seafood restaurant has to drink alcohol."

"Pakistani and African inexperienced waiters, tasteless appetizers and overcooked fish, high prices, and the rude management will ruin your night. Stay away!"

The category with the third highest number of negative reviews according to the table is the price category ( 26 negative reviews- $19 \%$ ). Three of these negative reviews are as follows:

"Frozen seafood is served in an amateur manner. You can't satisfy your hunger, and most importantly the prices are very high."

"The dishes and service had fast food quality, but they were still too expensive. One piece of cheese wedge was $10 \mathrm{TL}$. Octopus was served in 3 pieces with a price of $55 \mathrm{TL}$. There are much more quality venues in the harbour at much more affordable prices."

"Very very expensive; the worst ink fish I have ever eaten in my life; It was disgusting; I do not recommend this restaurant to anyone if you don't want to waste your money." 
Journal of Business Management and Economic Research (JOBMER), vol.3, issue.7, pp.33-45

The category with the fourth highest number of negative reviews according to the table is the service category (22 negative reviews- 16\%). These negative reviews are mostly about 'poor service' (14 negative reviews, 64\%) and 'slow service' (8 negative reviews- 36\%). Three of these negative reviews are as follows:

"The restaurant has a nice view, but the service is very unsuccessful. Although there were only 2-3 tables, the waiters were unresponsive. The taste of the dishes is not bad but ordinary."

"Bad appetizers, poor service! If a waiter is new, he should get full training. Do the service properly. If four waiters cannot deal with three tables and customers wait for water for minutes, you must close the restaurant."

"It was a big disappointment. Service sucks. Plates, forks, knives ... They don't know how to serve. The tablecloth wasn't even clean. We waited for 5 minutes for a waiter. And it was not cheap."

The category with the fifth highest number of negative reviews according to the table is the service environment category ( 8 negative reviews- $6 \%$ ). These negative reviews are mostly about insufficient cleaning (4 negative reviews, 50\%), noise (2 negative reviews, $25 \%$ ), insufficient technology (1 negative review, 12,5\%), and insufficient equipment (1 negative review, 12,5\%). Three of these negative reviews are as follows:

"We were not satisfied with neither the dishes, nor service, or hygiene. Prices were higher than should be; we tried the restaurant for once but will never go there again. Apparently, one should not eat seafood in the Port of Kyrenia in the near future."

"It is like a fast food restaurant with noise and abundant smoke. I didn't know that the grilled octopus was an octopus; it scattered like thick cheese. I do not recommend anyone."

"I went there at night on the 1st of February. They served the main course 2 hours late. To make us leave the restaurant after $11 \mathrm{pm}$, they closed the electric heaters (saying that there was a problem) and said that the wireless had a problem."

The category with the least number of negative reviews according to the table is the insufficient menu category ( 8 negative reviews- $6 \%$ ). Three of these negative reviews are as follows:

"Excellent location and good service. But the menu was rather boring."

"If the menu doesn't contain something you order, the waiters should tell that it does not. When you ask a waiter something in that restaurant, the waiter does not come back to answer you." 
"The dishes were delicious, and there were plenty of choices, but there were not as many wine options. We had to drink the wine we did not like."

\section{Discussion and Conclusion}

\subsection{Theoretical implications}

The Internet has now become a tool that affects consumer behavior and purchasing decision beyond communication and access to information. In terms of businesses operating in the service sector, the Internet offers many opportunities and applications to find new customers and to strengthen their relations with existing customers. Nowadays, it is common for consumers to make decisions by examining the comments and recommendations made on the internet about the product or service they are considering to make before making a purchase decision. In other words, consumers make the final purchase decision after their research on the internet. Therefore, the evaluations made by the users of the product or service via social networks are extremely important for businesses. The responses to these evaluations, as well as the evaluations, are closely monitored by potential customers, in particular the manner of communication against dissatisfied customers who have a negative opinion.

The "tripadvisor.com", one of the social networks on the internet, is one of the most critical websites for businesses operating in all areas of tourism. The "tripadvisor.com" provides its users with the opportunity to review and rate businesses' services and is therefore highly effective today in purchasing decision of many consumers. In this respect, reviews on this site, especially negative reviews, are essential for businesses.

In this research, negative reviews written on tripadvisor.com about the seafood restaurants in Kyrenia were examined. The average of the rating of the restaurants is 4.14 on a 5 point scale. This average indicates high satisfaction. Customers wrote 938 reviews about the restaurants. Of the customers who wrote these reviews, 585 (62\%) rated their experience as excellent, $223(24 \%)$ as very good, $66(7 \%)$ as average, $24(3 \%)$ as poor, and $40(4 \%)$ as terrible. These ratings also indicate high satisfaction.

On the other hand, of all the reviews, 137 are negative. Of the customers who wrote these negative reviews, $4(3 \%)$ rated their experience as excellent, $8(6 \%)$ as very good, $61(45 \%)$ as average, 24 $(18 \%)$ as poor, and $40(29 \%)$ as terrible. 
Furthermore, of these negative reviews, $42(30 \%)$ are about the dishes, 31(23\%) about the staff, 26 $(19 \%)$ about the prices, $22(16 \%)$ about the service, $8(6 \%)$ about the service environment, and 8 $(6 \%)$ about the menus.

\subsection{Practical implications}

Considering that the negative reviews are mostly about cooking mistakes and the taste of the dishes, it can be understood that the negative reviews are essentially about the staff. With more qualified staff and adequate audits, the number of these negative reviews can be reduced. Also, the high percentage of negative reviews about the staff $(23 \%)$ indicates the necessity for the employment of more qualified staff. Considering that the percentage of total negative reviews in the two dimensions is $53 \%$, we can argue that approximately half of the negative reviews will be prevented when the quality of the staff is increased. An effective audit of high prices and small sizes of portions will also prevent negative reviews about the prices and portions. Furthermore, qualified staff will use the cooking materials more efficiently, which, in turn, will probably lead to a reduction in costs. Poor and slow service is also one of the negative reviews related to the qualifications of the staff. These negative reviews can also be prevented by employing a sufficient number of qualified staff. Negative reviews such as 'insufficient technology or equipment' can be prevented through adequate investment in the service environment. Negative reviews about the hygiene of the restaurants can be prevented through effective audits. Also, negative reviews about 'insufficient menus' can be prevented by adding various dishes to the menus. Overall, the majority of negative reviews will be prevented through the employment of qualified staff.

\section{Limitations and directions for future research:}

This research only included sea food restaurants appearing in tripadvisor.com in Kyrenia, North Cyprus. Thus, the findings are limited to this destination. Sea food restaurants in other cities or destinations can differ from the studied enterprises due to dissimilarities in market competitiveness, and political conditions. Hence, further explorations may concentrate on other settings or comparative examination.

\section{References}


Barlow, J. \& Moller, C. (1998). A Complaint is a Gift (Her Şikâyet Bir Armağandır). Günhan Günay (tra.), İstanbul: Rota Yayınları.

Chen J., Teng, L., Yu, Y. \& Yu, X., (2016). The effect of online information sources on purchase intentions between consumers with high and low susceptibility to informational influence. Journal of Business Research, 69(2): 467-475.

Crie, D. (2003). Consumers' complaint behaviour. taxonomy, typology and determinants: towards a unified ontology. Database Marketing \& Customer Strategy Management, 11(1): 60-79.

Dahl, A. \& Peltier, J., (2015). A historical review and future research agenda for the field of consumer satisfaction, dissatisfaction, \& complaining behavior. Journal of Consumer Satisfaction, Dissatisfaction, \& Complaining Behavior, 28(2015): 5-25

DeFranco, A., Wortman, J., Lam. T. \& Countryman, C. (2005). A crosscultural comparison of customer complaint behaviour in restaurants in hotels. Asia Pacific Journal of Tourism Research, 10 (2):173-190.

Erkan, İ. \& Evans, C. (2016). The influence of e-wom in social media on consumers' purchase intentions: An extended approach to information adoption. Computers in Human Behavior, 61: 47-55.

Fornell, C. \& Westbrook, R.A. (1979). An exploratory study of assertiveness, aggressiveness, and consumer complaining behavior. Advances in Consumer Research, 6:105-110.

Grougiou, V. \& Pettigrew, S., (2009). Seniors' attitudes to voicing complaints: a qualitative study. Journal of Marketing Management, 25(9-10): 987- 1001.

Hennig-Thurau, T., Gwinner, K. P., Walsh, G. \& Gremler, D. D. (2004). Electronic word-of-mouth via consumer-opinion platforms: What wotivates consumers to articulate themselves on the internet?. Journal of Interactive Marketing, 18(1): 38-52.

Hussain, S., Guangju, W., Muhammad, R., Jafar, S., Ilyas, Z., Mustafa, G. \& Jianzhou, Y. (2018). Consumers' online information adoption behavior: motives and antecedents of Electronic word of mouth communications. Computers in Human Behavior, 80: 22-32.

Hussain S., Ahmed, W., Muhammad, R., Jafar, S., Rabnawaz, A. \& Jianzhou, Y. (2017). e-WOM source credibility, perceived risk and food product customer's information adoption. Computers in Human Behavior, 66: 96-102.

Jacoby, J. \& Jaccard, J.J., (1981). The sources, meaning, and validity of consumer complaint behavior: a psychological analysis. Journal of Retailing, 57 (3):4-24.

Jeong, E. H. \& Jang, S.C.(2011). Restaurant experiences triggering positive electronic wordofmouth (eWOM). Motivations.International Journal of Hospitality Management, 30(2): 356366.

Kim, C., Kim,S., Im, S. \& Shin, C. (2003). The effect of attitute and perception on consumer complaint intentions. Journal of Consumer Marketing, 20(4):352-371.

Mattila, A.S. \& Wirtz, J. (2004). Consumer complaining to firms: The determinants of channel choice. Journal of Service Marketing, 18 (2):147-155.

Meyer, C. \& Schwager A.,(2007). Understanding customer experience. Harvard Business Review, 85(2): $116-126$. 
Moore, Sarah G. (2015). Attitude predictability and helpfulness in önline reviews: The role of explained actions and reactions. Journal of Consumer Research, 42 (1): 30-44.

Morgan, R. M. \& Hunt, S. D., (1994). The commitment-trust theory of relationship marketing. Journal of Marketing, 58(3): 20-38.

Nielsen (2015), "Global trust in advertising: winning strategies for an evolving media landscape," http://www.nielsen.com/ us/en/insights/reports/2015/global-trust-in-advertising-2015. html.

Quan, S. \& Wang, N.,(2004). Towards a structural model of the tourist experience:an illustration from food experiences in tourism. Tourism Management, 25(3): 297-305.

Raguseo, E., Neirotti, P. \& Paolucci, E. (2017). How small hotels can drive value their way in infomediation: The case of Italian hotels vs. Otas and Tripadvisor'. InformationE. Management, 54 (6): 745-756.

Richins, M. L., (1983). An analysis of consumer interaction styles in the Marketplace. Journal of Consumer Research, 10(1): 73-82.

Richins, M.L., (1987). A multivariate analysis of responses to dissatisfaction. Journal of the Academy of Marketing Science, 15(3): 24-31.

Singh, J., (1988). Consumer complaint intentions and behavior: Definitional and taxonomical issues. Journal of Marketing, 52(1): 93-107.

Singh, J., (1990). A typology of consumer dissatisfaction response styles. Journal of Retailing, 66(1): 57-99.

Singh, J. \& Pandya, S. (1991). Exploring the effects of consumers' dissatisfaction level on complaint behaviours. European Journal of Marketing, 25(9): 7-21.

Sotiriadis, M. D. \& Zyl, C.V. (2013). Electronic word-of-mouth and online reviews in tourism services: The use of Twitter by tourists. Electronic Commerce Research, 13(1): 103-124.

Sparks, B. A. \& Bradley, G. L. (2014). A “triple a" typology of responding to negative consumergenerated online reviews. Journal of Hospitality and Tourism Research, 41(6): 719-745.

Xiang, Z., Du, Q., Ma, Y. \& Fan, W. (2017). A comparative analysis of major online review platforms: Implications for social media analytics in hospitality and tourism. Tourism Management, 58: 51-65.

Xiang, Z. \& Gretzel, U. (2010). Role of social media in online travel information search. Tourism Management. 31(2), 179-188.

Westbrook, R.A. (1980). Intrapersonel affective influences on consumer satisfaction with products. Journal of Consumer Research, 7(1): 49-54.

Zeng, B. \& Gerritsen, R. (2014). What do we know about social media in tourism? A review. Tourism Management Perspectives, 10, 27-36. 